\title{
AACO technique for solving multiobjectives in electrical distribution system
}

\author{
P. Ravi Babu, Molughu Srivani \\ Department of Electrical and Electronics Engineering, Sreenidhi Institute of Science and Technology, India
}

\begin{tabular}{l} 
Article Info \\
\hline Article history: \\
Received Sep 16, 2018 \\
Revised Nov 17, 2018 \\
Accepted Feb 22, 2019 \\
\hline
\end{tabular}

\section{Keywords:}

Artificial ant colony

optimization

Direct load flow

Electrical distribution system

Load balance index

Probabilistic transition rule

Reconfiguration

Service restoration

\begin{abstract}
The multi objectives in electrical distribution system are service restoration and minimization of Ohmic losses. These objectives can be achieved by artificial ant colony optimization through reconfiguration. Service restoration is also a major aspect for reliable service. If any fault occurs in the system, faulted zone is isolated from healthy system. This originates discontinuity in power supply. To maintain the continuity in power supply there is a necessity to provide service to these loads from adjacent healthy feeders through reconfiguration without infringement of radiality, load balance and critical parameters. In distribution system Ohmic losses are 30 to 40 percent. In order to minimize these losses, there is a need for reconfiguration of the system and perform the power flow analysis to get bus voltages, branch currents and power losses (i.e. real or Ohmic or copper loss and reactive power loss). A direct load flow analysis is adopted in the proposed work. In this paper IEEE four feeder test system used for service restoration and IEEE 33 bus, IEEE 69 bus test systems for minimization of Ohmic losses have been obtained.
\end{abstract}

Copyright $\odot 2019$ Institute of Advanced Engineering and Science. All rights reserved.

\section{Corresponding Author:}

Molughu Srivani,

Department of Electrical and Electronics Engineering,

Sreenidhi Institute of Science and Technology,

Yamnampet, Ghatkesar, Hyderabad, Telangana, India 501301.

Email: srivanimolughu@gmail.com, ravi.dsm@gmail.com

\section{INTRODUCTION}

Generation, transmission and distribution are the three stages of electrical power system. Generating power at generating station is transmitted through transmission lines and given to distribution network. It distributes power to loads connected to distribution network. Electrical distribution system is operated for lower voltages compared to transmission system. Because of lower voltage, higher currents pass in distribution system this lead to higher real power loss compared to generation and transmission systems. Distribution system is operated with fixed voltage and variable current magnitudes. In any environment three main important factors are existed. Those are security, reliability, efficiency (priority of choosing among three are security, reliability, efficiency).

If any fault occurred in system, that may create cascade shutdown then overall system collapse. To avoid this should take immediate actions. Actions are may be isolated faulted zone in the system and give supply to remaining loads from healthy feeders, in some cases the remaining healthy feeders are already in overload condition then go for load shutdown at this moment system safety important role. This is nothing but service restoration, this may not provide $100 \%$ continuous power supply but somehow it maintains both reliable supply and system safety.

The apparent power loss is equal to sum of real and reactive power losses. If power losses (apparent power loss) increases then real and reactive power losses also increases. Real power loss is more means system with less efficient. Reactive power is directly proportional to square of voltage in the system. 
If reactive power is more, then voltage in the system more this lead to insulation breakdown on conductor finally dead short circuit will occur then overall system collapse, so need to maintain minimum apparent loss then it results good efficiency and voltage in the system.

Power loss reduction formula is derived by Civanlar \& Grainger [1], in this paper power loss reduction and reduced computation time done by using "branch interchange" algorithm. D. Shirmohammadi $\&$ H. W. Hong [2], in this paper the researcher focused on both resistive loss reduction and reduced computed time using DISTOP methodology. M.E. Baran \& F.Wu [3], in this paper author applies two different load flows for the sake of accuracy and computation time. Both loss reduction and load balance achieved by using approximated power flow methods. Taylor, Lubkeman [4], developed a rule -based system aimed at the reduction of both search space and real power loss. J.Z. Zhu [5], presented to study distribution network reconfiguration based on refined genetic algorithm. A radiation distribution network load flow method is used to calculate power losses and objective is to minimize the system power loss. Jorge Mendoza et al [6], proposes a formal and robust strategy for applying the large optimal reconfiguration problems using genetic algorithm. The main objective is to power loss minimization through reconfiguration. The problems of overloading and service restoration, unbalanced load on electrical distribution system can be solved through reconfiguration by using ant colony optimization and heuristic search technique [7], [8] respectively. F.S Pereira, K. Vittori et al [9], proposed meta heuristic methodology for reconfiguration of electrical distribution system to minimize power loss. In this paper two algorithms ant colony optimizationtravelling salesman and ant colony optimization-radial system reconfiguration are applied to one common standard five bus sample system. Finally author justified ant colony optimization-radial system reconfiguration is best for reconfiguration. Majid Jamil et al [10], proposed for the restoration of electrical distribution system in the overload condition with minimum power loss by using ant colony system algorithm. Firas M.F.Flaih,Lin, Lin Xiangning et al [11], presented the power loss minimization and voltage profile improvement in distribution system by using modified particle swarm optimization, modified particle swarm optimization was applied on the standard IEEE 33-bus test system. Other heuristic methods have been published that are principally based on switch selection(reconfiguration) done by using modified particle swarm optimization, Multi-Cooperative Particle Swarm Optimization, Selective Particle Swarm Optimization algorithms solved for IEEE $33 \& 69$ bus test systems. The objective function is to power loss minimization and approximate formulas for losses evaluation as those presented in [12], [13] and [14] respectively. S.Ganesh and R.Kanimozhi [15], proposed a new method for network reconfiguration in distribution system based on ant colony optimization with objective of real power loss minimization for 33-bus single feeder distribution network with five different kinds of load levels. Real loss minimization through reconfiguration of radial distribution system in both normal and abnormal conditions done with Improved Particle Swarm Optimization was projected by Dusharal Venkata Sunil et al [16].

In this paper, reconfiguration of distribution system has been formulated by using Artificial Ant Colony Optimization technique. Next output of any system with linear characteristics can be easily predicted but practically linear behaviour is not present. Nonlinear behaviour cases cannot predict next output, as it is very complex. This technique gives the solution to nonlinear problems, reduces time consumption and gives accurate results. This technique is co-related with electrical distribution system as current matches with ant's movement, pheromone intensity matches with power flow and length of the line with resistance or time consumption. Two objectives are met, first one is service restoration and second one is real power loss minimization. The proposed work is organized into six sections, first Section-1 is introduction, Section 2 on problem formulation, Section 3 discusses proposed technique algorithm for reconfiguration, and Section 4 discussed proposed method applications on test systems. Section 5 on results and finally conclusions are in Section 6.

\section{PROBLEM FORMULATION}

\subsection{Service Restoration}

First identify faulted feeder, isolate the fault. Identify the affected zones due to fault, which are out of service. Reconfigure the system with LBI calculations using (1).

$$
L B I=\frac{1}{n} \sqrt{\sum\left(Y-Y_{i}\right)^{2}}
$$

Where: $n=$ no. of primary feeders; $Y=$ average of the normalized loadings $Y_{i}$

$$
Y_{i}=\frac{i^{\text {th }}-\text { Feeder Actual Loading }}{\mathrm{i}^{\text {th }}-\text { Feeder Base Loading }} ; \mathrm{i}=1,2,3 \ldots \mathrm{n}
$$


Subjected to following constraints:

$\mathrm{S}_{\mathrm{i}} \leq \mathrm{S}_{\mathrm{Ri}}$

$\mathrm{P}_{\mathrm{i}} \leq \mathrm{P}_{\mathrm{Ri}}$

$\mathrm{Q}_{\mathrm{i}} \leq \mathrm{Q}_{\mathrm{Ri}}$

Where: $\mathrm{i}=1,2,3 \ldots \mathrm{n} ; \mathrm{n}=$ no. of primary feeders

$\mathrm{S}_{\mathrm{i}}=$ MVA loading on feeder $-\mathrm{i} ; \mathrm{S}_{\mathrm{Ri}}=$ Rated MVA on feeder $-\mathrm{i}$

$\mathrm{P}_{\mathrm{i}}=\mathrm{MW}$ loading on feeder $-\mathrm{i} ; \mathrm{P}_{\mathrm{Ri}}=$ Rated MW loading on feeder $-\mathrm{i}$

$\mathrm{Q}_{\mathrm{i}}=$ MVAR loading on feeder $-\mathrm{i} ; \mathrm{Q}_{\mathrm{Ri}}=$ Rated MVAR on feeder $-\mathrm{i}$

In each and every reconfiguration load should be in balance condition, radiality and critical parameters with in permissible limits. Among all possible combinations which one gives least LBI value and satisfies all critical parameters that is the optimal solution.

\subsection{Power Flow Analysis - Direct Load Flow Method (DLFM)}

This method performs the power flow analysis for weakly meshed distribution system under balanced operating condition employing constant load model. In this method three steps are present, those are

a. Equivalent current injection

b. Formation of BIBC matrix

c. Formation of BCBV matrix

\subsubsection{Equivalent Current Injection}

It is purely based on current injection. At $\mathrm{i}^{\text {th }}$ bus, the apparent power $\mathrm{S}_{\mathrm{i}}$ is specified and the corresponding equivalent current injection at the $\mathrm{n}^{\text {th }}$ iteration of the solution is computed as:

$$
\begin{aligned}
& S_{i}=P_{i}+j Q_{i} \\
& I_{i}^{n}=\left(I_{i}^{R e a l} V_{i}^{n}\right)+j\left(I_{i}^{I m g} V_{i}^{n}\right)=\left(\frac{S_{i}}{V_{i}^{n}}\right)^{*}
\end{aligned}
$$

Where: $\mathrm{i}=1,2,3,4 \ldots \mathrm{N}$

$S_{i}$ is the apparent power at $i^{\text {th }}$ bus; $P_{i}$ is the real power at $i^{\text {th }}$ bus.

$Q_{i}$ is the reactive power at $i^{\text {th }}$ bus; $V_{i}^{n}$ is the bus voltage at the $n^{\text {th }}$ iteration for $i^{\text {th }}$ bus.

$I_{i}^{n}$ is the equivalent current injection at the $\mathrm{n}^{\text {th }}$ iteration for $\mathrm{i}^{\text {th }}$ bus.

$I_{i}^{\text {Real }} \& I_{i}^{n}$ are the real and imaginary parts of the equivalent current injection at the $\mathrm{n}^{\text {th }}$ iteration for $\mathrm{i}^{\text {th }}$ bus.

\subsubsection{Formation of BIBC Matrix}

In Figure 1 is used as an example to understand the formation of BIBC matrix. Using (3) apply Kirchhoff current law (KCL) to distribution network.

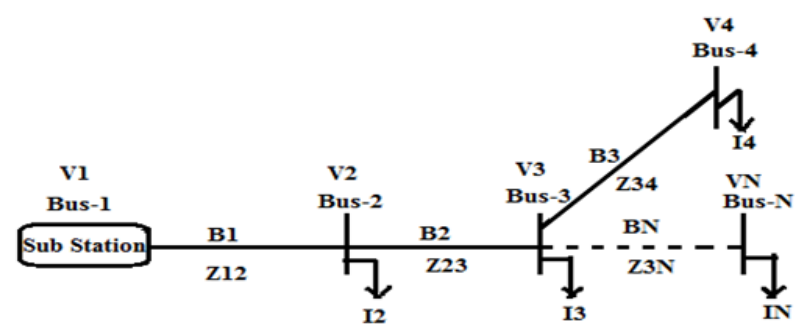

Figure 1. A simple weakly meshed distribution system

$$
\begin{aligned}
& \mathrm{B} 1=\mathrm{I} 2+\mathrm{I} 3+\mathrm{I} 4 \\
& \mathrm{~B} 2=\mathrm{I} 3+\mathrm{I} 4 \\
& \mathrm{~B} 3=\mathrm{I} 4
\end{aligned}
$$

Above (4), (5), (6) can be written in matrix form. This matrix is nothing but BIBC (Bus Injection to Branch Current) matrix as shown below (7). 


$$
\left[\begin{array}{l}
B_{1} \\
B_{2} \\
B_{3}
\end{array}\right]=\left[\begin{array}{lll}
1 & 1 & 1 \\
0 & 1 & 1 \\
0 & 0 & 1
\end{array}\right]\left[\begin{array}{l}
I_{2} \\
I_{3} \\
I_{4}
\end{array}\right]
$$

$[\mathrm{B}]=[\mathrm{BIBC}]_{\mathrm{MX}(\mathrm{N}-1)}[\mathrm{I}]$

Where:

$\mathrm{B} 1, \mathrm{~B} 2, \mathrm{~B} 3 \ldots . . \mathrm{BN}$ are the branch currents.

$\mathrm{V} 1, \mathrm{~V} 2, \mathrm{~V} 3 \ldots . \mathrm{VN}$ are the bus voltages.

$\mathrm{Z12}, \mathrm{Z23}, \mathrm{Z34} \ldots \mathrm{Z} 3 \mathrm{~N}$ are the branch impedances between 1and2, 2 and 3, 3 and 4, 3 and $\mathrm{N}$ respectively. $\mathrm{I} 2, \mathrm{I} 3, \mathrm{I} 4 \ldots \ldots \ldots \mathrm{IN}$ are the load currents.

$\mathrm{M}$ is the number of branches.

$\mathrm{N}$ is the number of buses.

\subsubsection{Formation of BCBV Matrix}

BCBV matrix nothing but, it is the relation between branch currents and bus voltage.

$$
\begin{aligned}
& \mathrm{V} 1=\mathrm{V} 2+(\mathrm{B} 1 * \mathrm{Z} 12) \\
& \mathrm{V} 2=\mathrm{V} 3+(\mathrm{B} 2 * \mathrm{Z} 23) \\
& \mathrm{V} 3=\mathrm{V} 4+(\mathrm{B} 3 * \mathrm{Z} 34)
\end{aligned}
$$

By using above (9), (10) and (11) the voltage at Bus-4 can be rewritten as

$$
V_{4}=V_{1}-\left(B_{1} Z_{12}\right)-\left(B_{2} Z_{23}\right)-\left(B_{3} Z_{34}\right)
$$

Above (9), (10), (11) and (12) can be written in matrix form. This matrix is nothing but BCBV (Branch current to Bus Voltage) matrix as shown below (13).

$$
\begin{aligned}
& {\left[\begin{array}{l}
\mathrm{V}_{1} \\
\mathrm{~V}_{1} \\
\mathrm{~V}_{1}
\end{array}\right]-\left[\begin{array}{l}
\mathrm{V}_{2} \\
\mathrm{~V}_{3} \\
\mathrm{~V}_{4}
\end{array}\right]=\left[\begin{array}{ccc}
\mathrm{Z}_{12} & 0 & 0 \\
\mathrm{Z}_{12} & \mathrm{Z}_{23} & 0 \\
\mathrm{Z}_{12} & \mathrm{Z}_{23} & \mathrm{Z}_{34}
\end{array}\right]\left[\begin{array}{l}
\mathrm{B}_{1} \\
\mathrm{~B}_{2} \\
\mathrm{~B}_{3}
\end{array}\right]} \\
& {[\Delta \mathrm{V}]=[\mathrm{BCBV}]_{(\mathrm{N}-1) \mathrm{XM}}[\mathrm{B}]} \\
& \mathrm{I}_{\mathrm{i}}^{\mathrm{n}}=\left[\frac{\mathrm{P}_{\mathrm{i}}+\mathrm{Q}_{\mathrm{i}}}{\mathrm{V}_{\mathrm{i}}}\right]^{*}
\end{aligned}
$$

Update voltages using (14), Calculate DLF (direct load flow) matrix using (16)

$$
[\Delta \mathrm{V}]^{\mathrm{n}+1}=[\mathrm{DLF}][\mathrm{I}]^{\mathrm{n}}
$$

Set iteration count $n=0$, if $\left|\left[\mathrm{I}_{\mathrm{i}}^{\mathrm{n}+1}-\mathrm{I}_{\mathrm{i}}^{\mathrm{n}}\right]\right|<\xi$ (tolerance value) then calculate line flows and losses using final voltages. Otherwise go for iteration number increment $(n=n+1)$ and follow above same procedure.

Subject to the following constraints:

a. Radiality to be maintained.

b. Number of tie switches before and after reconfiguration should not change.

c. Voltage Magnitude:

$$
\mathrm{V}_{\min } \leq\left|\mathrm{V}_{\mathrm{i}}\right| \leq \mathrm{V}_{\max } ; \mathrm{i}
$$

Where:

$V_{i}$ is the voltage on $i^{\text {th }}$ bus; $N_{R}$ is the number of branches in the system; $N_{b}$ is the number of buses in the system. These constraints are applicable to all Objectives. 


\section{PROPOSED TECHNIQUE - ARTIFICIAL ANT COLONY OPTIMIZATION (AACO)}

\subsection{Introduction}

This technique gives solution to nonlinear problems related to any field of work. Natural living behavior of ants gives optimal solution either a minimal or a maximal of main objective of problem is called Ant Colony Optimization.

When an ant moves to search for food from home to food source it deposits chemical substance on ground called as pheromone. This substance is a clue for other ants from the same home to collect the food. Ants follow the pheromone trails left by the first ant. From home to food source the ants have several paths with variable pheromone trails. Among those trails ants choose higher pheromone intensity path. This path is also attracted by remaining ants. Always ants prefer shortest path (i.e. higher pheromone intensity).

Figures 2 and 3 represent ant colony system without and with obstacle. Thicker line indicates higher pheromone intensity as a shorter path, thinner line indicates less pheromone intensity as a longer path.

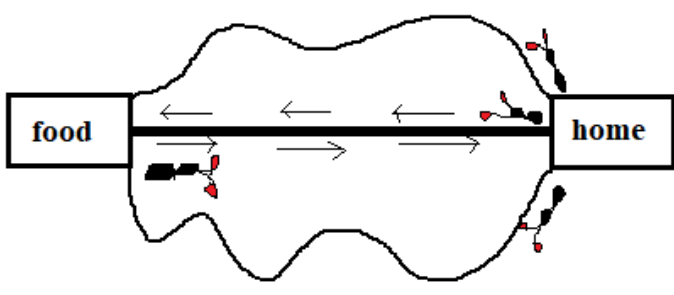

Figure 2. Natural behavior of ant without obstacle

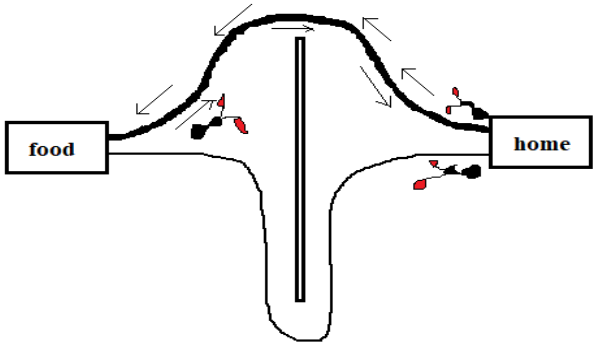

Figure 3. Natural behavior of ant with obstacle

Electrical Distribution System having $n=$ number of switches and total possible combinations for reconfiguration are $2^{n}$.In order to reduce time consumption for this possible reconfigurations ACO itself has probabilistic transition rule (PTR).

PTR measures ant probability of choosing path among all possible paths. For example when a system has 10 switches then total number of possible combinations for reconfiguration are $2^{10}=1024$. Using PTR this may reduce to 15 possible combinations for reconfiguration and gives optimal solution.

PTR is formulated as (18)

$$
P_{i, j}^{k}(t)=\frac{\left[\tau_{i, j}(t)\right]^{\alpha}\left[\eta_{i, j}(t)\right]^{\beta}}{\sum_{1}\left[\tau_{i, j}\right]^{\alpha}\left[\eta_{i, j}\right]^{\beta}}
$$

Where: $\mathrm{j}, \mathrm{q} \in \mathrm{N}_{\mathrm{i}}^{\mathrm{k}}$.

$\mathrm{N}_{\mathrm{i}}^{\mathrm{k}}$ is a list in the memory of ant that records the cities which will be visited to avoid stagnations.

$\mathrm{i}, \mathrm{j}$ is the travel path of ants; $\tau_{\mathrm{i}, \mathrm{j}}=$ pheromone trail deposited between the nodes $\mathrm{i}, \mathrm{j}$.

$\eta_{i, j}==$ represents the heuristic information $=\frac{1}{\mathrm{~d}_{\mathrm{i}, \mathrm{j}}} ; \mathrm{d}_{\mathrm{i}, \mathrm{j}}=$ distance between city $\mathrm{i}$ and $\mathrm{j}$.

$\propto, \beta=$ Are two parameters that influence the relative weight of pheromone trail and heuristic guide function respectively.

After each tour is completed a local pheromone update is determined as below mentioned (19). It is the sum of old pheromone intensity $\left(\rho \cdot \tau_{i, j}(t)\right)$ and new pheromone intensity $\left(\Delta \tau_{i, j}\right)$.

$$
\tau_{i, j}(t+1)=\left(\rho . \tau_{i, j}(t)+\left(\Delta \tau_{i, j}\right)\right.
$$

Where:

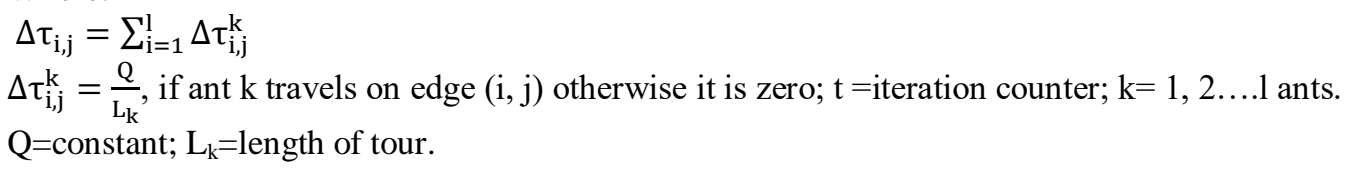




\subsection{Flow Chart}

Flowchart of proposed method is shown in Figure 4.

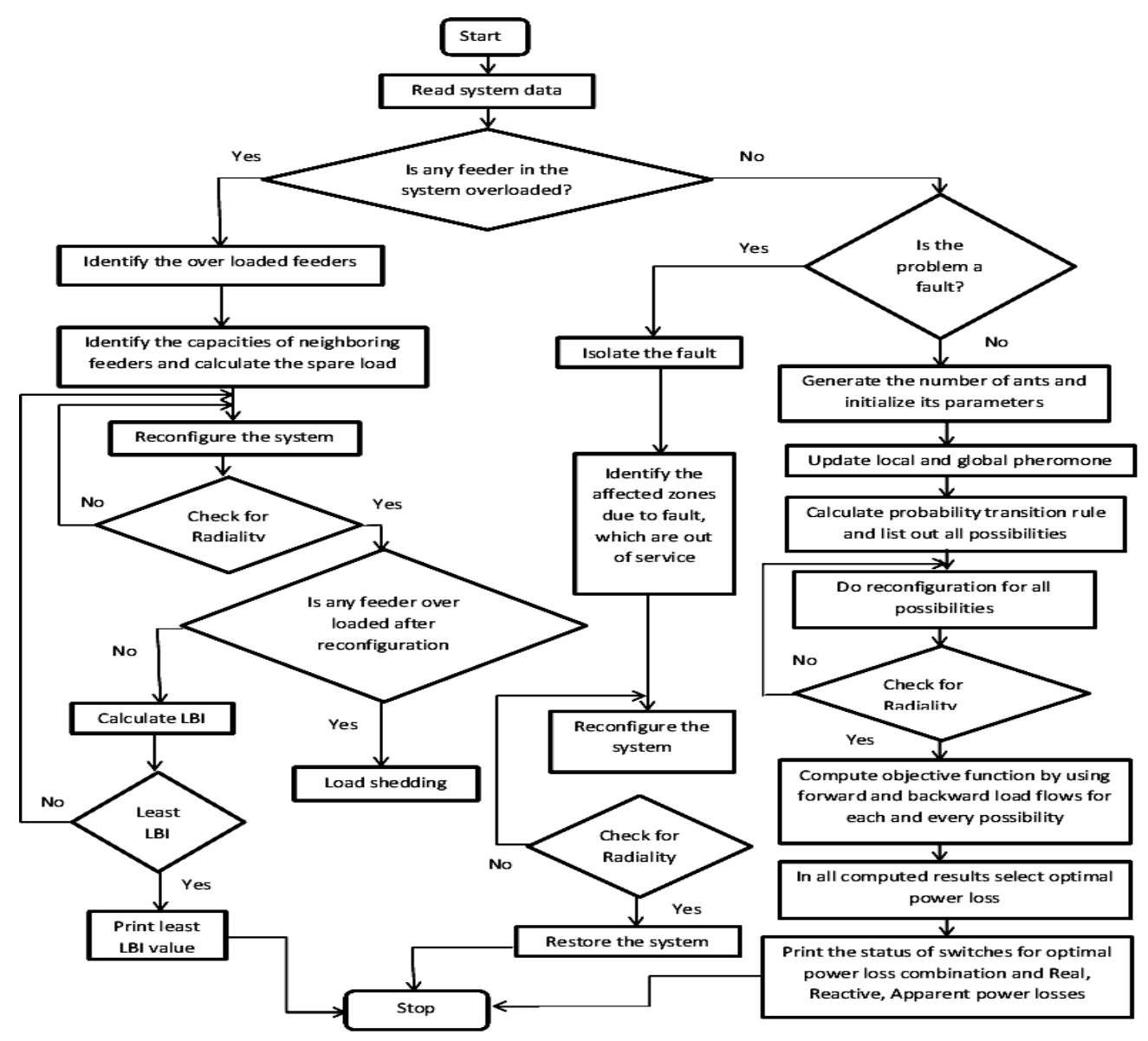

Figure 4. Flowchart of proposed method

\section{PROPOSED METHOD}

The proposed AACO method is tested on four feeder service restoration, Ohmic loss minimization of IEEE 33 bus and 69 bus test systems. Test results as follows below.

\subsection{IEEE Four Feeder Service Restoration}

The proposed AACO technique is tested on the IEEE four feeder test system is shown in Figure 5, in this 16 sectionalized switches are generally in closed condition(between zone loads example-switches $2,3,4 \ldots$ ) and 15 tie switches are generally open condition (between zone loads of different feeders exampleswitches $6,7,8 \ldots)$. Each feeder loading capability is $10,000 \mathrm{kVA} .1,11,21,31$ are the circuit breakers of four feeders in the system. Table 1 shows the zone loads.

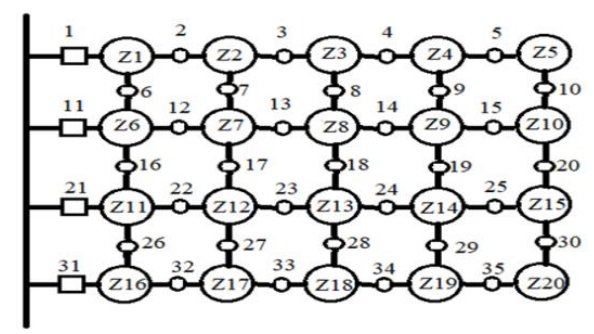

Figure 5. Four feeder test system 


\begin{tabular}{cc} 
Table 1. Four Feeder Load Data \\
\hline Zone number & Zone load(kVA) \\
\hline 1 & 1600 \\
2 & 700 \\
3 & 1800 \\
4 & 500 \\
5 & 1900 \\
6 & 500 \\
7 & 1500 \\
8 & 1000 \\
9 & 500 \\
10 & 800 \\
11 & 3000 \\
12 & 3500 \\
13 & 700 \\
14 & 1000 \\
15 & 600 \\
16 & 1500 \\
17 & 2000 \\
18 & 1800 \\
19 & 1500 \\
20 & 500 \\
\hline
\end{tabular}

From Figure 5, each feeder capacity is $10000 \mathrm{kVA}$ and actual load on feeder A, B, C and D is 6500 kVA, $4300 \mathrm{kVA}, 8800 \mathrm{kVA}, 7300 \mathrm{kVA}$ respectively. For illustration of the proposed technique, assume some random faults occur on four feeder system (i.e. feeder A, B, C and D at positions are Z1, Z8, Z14 and $\mathrm{Z} 17$ respectively).these random faults explained in below four cases.

Case-1: Fault on feeder A at switch-1(circuit breaker)

Because of fault at switch-1, faulted section is isolated by opening Switch-1(Circuit breaker).To maintain continuous power supply need to connect total (Or) at least some of critical loads are transfer to other healthy feeders.

Before Reconfiguration: load on feeder A is zero kVA, feeder B is $4300 \mathrm{kVA}$, feeder C is $8800 \mathrm{kVA}$ and feeder D is $7300 \mathrm{kVA}$.

After Reconfiguration: Switches 6, 20 are closed condition (sectionalized Switches), Switch 15 is in open condition (tie switch).Load on feeder A is zero kVA, feeder B is10000 kVA, feeder C is $9600 \mathrm{kVA}$ and feeder D is $7300 \mathrm{kVA}$.

Case-2: Fault on feeder B at position Z8

Because of fault, faulted section is separated by opening switches 13 and14. Discarded load on feeder B is $2300 \mathrm{kVA}$.

Before Reconfiguration: load on feeder A is $6500 \mathrm{kVA}$, feeder B is $2000 \mathrm{kVA}$, feeder C is $8800 \mathrm{kVA}$ and feeder D is $7300 \mathrm{kVA}$.

After Reconfiguration: switch 9 is in closed condition (sectionalized switch).

Load on feeder A is $7800 \mathrm{kVA}$, feeder B is $2000 \mathrm{kVA}$, feeder C is $8800 \mathrm{kVA}$ and feeder D is $7300 \mathrm{kVA}$.

Case-3: Fault on feeder $\mathrm{C}$ is at position Z13

Because of fault, faulted section is separated by opening switches 23 and 24. Discarded load on feeder $\mathrm{C}$ is $2300 \mathrm{kVA}$.

Before Reconfiguration: load on feeder A is $6500 \mathrm{kVA}$, feeder B is $4300 \mathrm{kVA}$, feeder C is $6500 \mathrm{kVA}$ and feeder D is $7300 \mathrm{kVA}$.

After Reconfiguration: switch 19,30 are in closed condition (tie switches),switch 35 open condition(i.e. Sectionalizing switch). Load on feeder A is $6500 \mathrm{kVA}$, feeder B is $6400 \mathrm{kVA}$, feeder C is $6500 \mathrm{kVA}$ and feeder D is $6800 \mathrm{kVA}$.

Case-4: Fault on feeder $\mathrm{C}$ is at position Z14

Because of fault, faulted section is separated by opening switches 24 and 25. Discarded load on feeder $\mathrm{C}$ is $1600 \mathrm{kVA}$.

Before Reconfiguration: load on feeder A is $6500 \mathrm{kVA}$, feeder B is $4300 \mathrm{kVA}$, feeder C is7200 kVA and feeder D is $7300 \mathrm{kVA}$.

After Reconfiguration: switch 20 is in closed condition (sectionalized switch).Load on feeder A is $6500 \mathrm{kVA}$, feeder B is $4900 \mathrm{kVA}$, feeder $\mathrm{C}$ is $7200 \mathrm{kVA}$ and feeder D is $7300 \mathrm{kVA}$.

Case-5: Fault on feeder D at position Z17

Because of fault, faulted section is separated by opening switches 32 and 33. Discarded load on feeder B is $5800 \mathrm{kVA}$. 
Before Reconfiguration: load on feeder A is $6500 \mathrm{kVA}$, feeder B is $4300 \mathrm{kVA}$, feeder C is $8800 \mathrm{kVA}$ and feeder D is $1500 \mathrm{kVA}$.

After Reconfiguration: switches 10, 19, 29 are in closed condition(Sectionalized switches) and switches 15, 24 are in open condition (tie switches).Load on feeder A is $7800 \mathrm{kVA}$, feeder B is $2000 \mathrm{kVA}$, feeder C is $8800 \mathrm{kVA}$ and feeder D is $7300 \mathrm{kVA}$.

\subsection{Minimization of Ohmic Losses}

\subsubsection{IEEE 33 Bus Test System}

The proposed technique was applied on IEEE 33 bus test system. The test system base voltage is $12.66 \mathrm{kV}$,base MVA - 100 and total system real and reactive loads are $3715 \mathrm{~kW}$ and $2300 \mathrm{kVAR}$, respectively, and it consists of five tie switches.

Before reconfiguration - Initial network configuration consists of S1 to S32 are the sectionalizing switches and S33 to S37 are the tie switches. For this combination real power, reactive power and apparent power losses are 202.6771kW, 135.1410 kVAR and 243.6 kVA respectively.

After reconfiguration - the optimal configuration obtained by the proposed algorithm is S29, S33, S34, S35, S37 are the tie switches (i.e. dotted lines) remaining all are the sectionalizing switches as shown in below Figure 6. For this combination real power, reactive power and apparent power losses are $109.6065 \mathrm{~kW}$, $78.0381 \mathrm{kVAR}$ and $134.5494 \mathrm{kVA}$ respectively. After (Optimal) reconfiguration, $45.9206 \%$ of loss reduction is obtained comparatively.

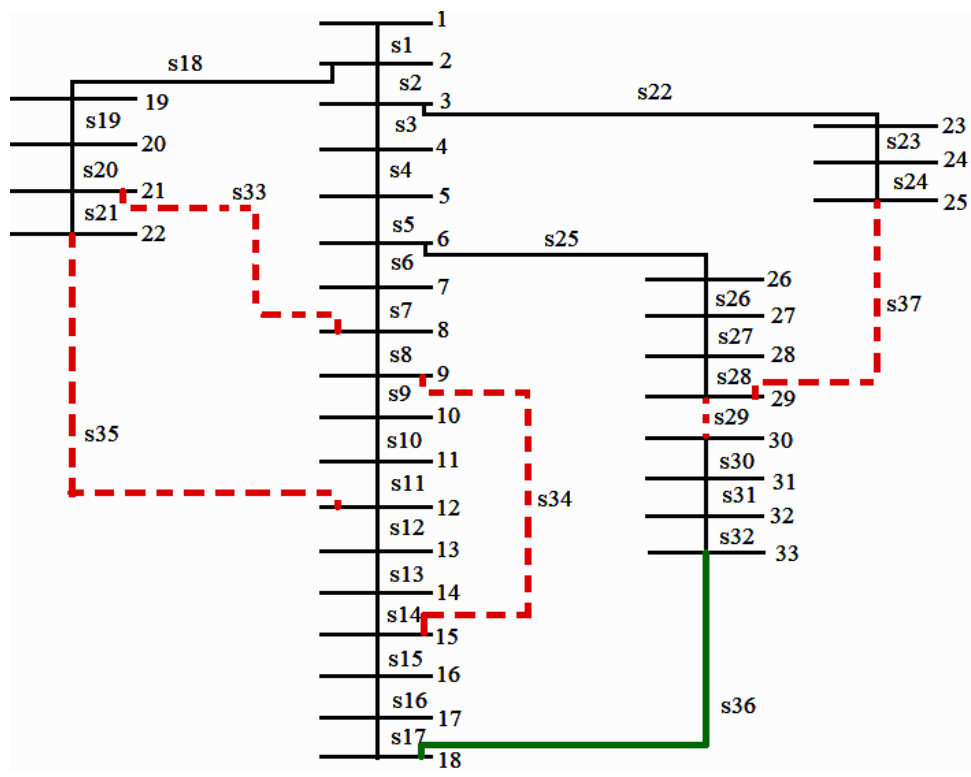

Figure 6. 33 Bus test system after reconfiguration

\subsubsection{IEEE 69 Bus Test System}

The proposed technique was applied on IEEE 69 bus test system. The test system base voltage is $12.66 \mathrm{kVA}$, base MVA-100 and total system real and reactive loads are $3802.19 \mathrm{~kW}$ and $2694.6 \mathrm{kVAR}$, respectively, and it consists of five tie switches.

Before reconfiguration-Initial network configuration consists of switches 1 to switch 68 are considered by the sectionalizing switches and switch 70 to switch 74 are the tie switches. For this combination real power, reactive power and apparent power losses are 225.0028kW, 102.1659 kVAR and 247.1116 kVA respectively.

After reconfiguration-switches 49, 64, 70, 71, 72 are the tie switches (i.e. dotted lines) remaining are the sectionalizing switches as shown in below Figure 7. For this combination real power, reactive power and apparent power losses are $71.1381 \mathrm{~kW}, 78.7572 \mathrm{kVAR}$ and 106.1288 kVA respectively. After (Optimal) reconfiguration, $68.3834 \%$ of loss reduction is obtained comparatively. 


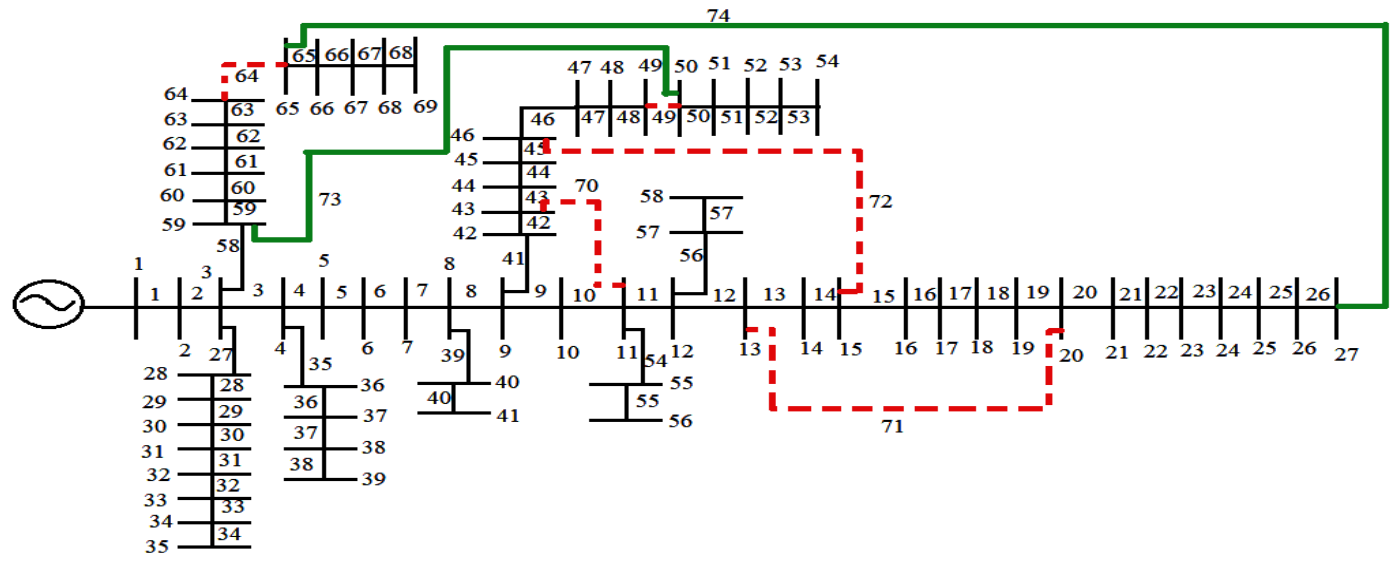

Figure 7. 69 bus test system after reconfiguration

\section{RESULTS}

\subsection{IEEE Four Feeder Service Restoration}

The simulation results of distribution system reconfiguration based on AACO for IEEE 4- feeder service restoration are shown in Table 2.

Table 2. Results of 4 Feeder System under Faulty Conditions at Different Locations

\begin{tabular}{cccc}
\hline Feeder & Fault at & Optimal switching operation & LBI \\
\hline A & Switch-1 & Closed Switches - 6\&20 & 0.200853 \\
& & Open Switch - 15 & \\
B & Z8 & Closed Switch - 9 & 0.131974 \\
C & Z13 & Closed Switches - 19\&30 & 0.0075 \\
& & Open Switch - 35 & \\
C & Z14 & Closed Switch - 20 & 0.048007 \\
D & Z17 & Closed Switches - 10,19\&29 & 0.140506 \\
& & Open Switches - 15\&24 \\
\hline
\end{tabular}

In IEEE four feeder test system, for same fault on feeder-C at position Z13. Continuity of power supply maintained, optimal LBI value of proposed method is compared with other reference papers LBI values, among those proposed method gives least LBI value as shown in below Table 3.

Table 3. Results Validation of Four Feeder System for Service Restoration

\begin{tabular}{cc}
\hline Method & LBI value for the same fault on feeder-C at position Z13 \\
\hline Dr.P.Ravi Babu[22] & 0.0100 \\
Dr.P.Ravi Babu[23] & 0.0124 \\
Proposed method & 0.0075 \\
\hline
\end{tabular}

\subsection{Minimization of Ohmic Losses}

In order to express the proposed method IEEE 33and 69 bus test systems are taken into consideration. The method is coded using MATLAB version R2017a is used to run the optimal power flow solver with direct load flow method. AACO is carried out best results, are shown in Table 4 and Table 5.

Table 4. Results Validation for 33 Bus Test System

\begin{tabular}{cccc}
\hline Method & Tie Switches & Loss After Reconfiguration(kW) & \% I ${ }^{2}$ R Loss Reduction \\
\hline J.Z.Zhu [5] & S7,S9,S14,S32,S33 & 139.532 & 31.1555 \\
Majid Jamil et al. [10] & S2,S13,S16,S33,S37 & 112.68 & 44.4041 \\
Firas M.F.Flaih et al. [11] & S7,S9,S14,S32,S37 & 139.55 & 31.1466 \\
proposed & S29,S33,S34,S35,S37 & 109.6065 & 45.9206 \\
\hline
\end{tabular}


Table 5. Results Validation for 69 Bus Test System

\begin{tabular}{cccc}
\hline Method & Tie Switches & Loss After Reconfiguration(kW) & \% I ${ }^{2}$ R Loss Reduction \\
\hline Inji Ibrahim atteya et al. [12] & $14,55,61,69,70$ & 100.6 & 55.2894 \\
Soumitri Jena et al. [13] & $12,18,58,61,69$ & 103.62 & 53.9472 \\
Tandon.A et al.[14] & $13,20,55,61,69$ & 107.05 & 52.4228 \\
proposed & $49,64,70,71,72$ & 71.1381 & 68.3834 \\
\hline
\end{tabular}

Improvement in Bus Voltages Before and After Reconfiguration of 33 Bus and 69 Bus Test Systems, as shown in Figure 8.

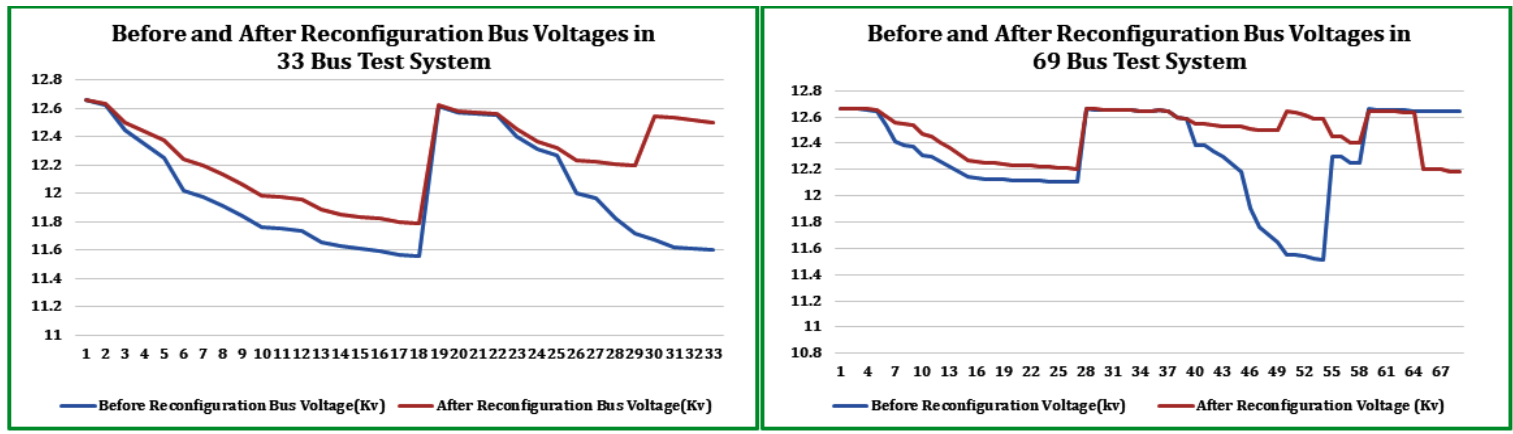

Figure 8. Bus voltages before and after reconfiguration of 33 bus and 69 bus test systems

\section{CONCLUSION}

Service restoration and Ohmic loss minimization in distribution system are the main objectives in this paper. Service restoration achieved on IEEE 4-feeder test system under faulty conditions at different locations and for the same fault at Z13 on feeder-C least LBI value is obtained with proposed technique compared to other reference papers. The Ohmic losses are minimized optimally in IEEE 33 and IEEE 69 bus test systems with $\mathrm{I}^{2} \mathrm{R}$ loss reduction by $45.9206 \%$ and $68.3834 \%$ respectively. The minimum voltage before reconfiguration is $11.5597 \mathrm{kV}$ at node-18 and after reconfiguration it is raised to $11.7876 \mathrm{kV}$ at node-18 for 33 bus test system. The minimum voltage before reconfiguration is $11.5103 \mathrm{kV}$ at node-54 and after reconfiguration it is raised to $12.181 \mathrm{kV}$ at node- 69 for 69 bus test system. These objectives achieved through reconfiguration by using artificial ant colony optimization (AACO).

\section{REFERENCES}

[1] Civanlar, J. J. Grainger, H. Yin \& S.S.H. Lee, “distribution feeder reconfiguration for loss reduction”, IEEE Trans. On power delivery, vol.3, No.3, July 1988, pp.1217-1223.

[2] Shirmohammadi and H.W.Hong, "reconfiguration of electric distribution networks for resistive line loss reduction", IEEE Trans. on power apparatus and systems Vol.4, No.2, 1989, pp.1492-1498.

[3] M.E.Baran \& F.Wu, "network reconfiguration in distribution systems for loss reduction \&load balancing", IEEE Trans. power Del., 1989, 4(2), pp.1401-1407.

[4] Taylor, D. Lubkeman, "implementation of heuristic strategies for distribution feeder reconfiguration", IEEE Trans. on power Del., Vol.5, No.1, Jan.1990, pp.239-245.

[5] J.Z.Zhu, "optimal reconfiguration of electrical distribution network using refined genetic algorithm", Electrical Power System Research, vol.62, pp.3202, 2002.

[6] Jorge Mendoza, Rodrigo Lopez et al., "minimum loss reconfiguration using genetic algorithms with restricted population \& addressed operators: Real application", IEEE, 2006.

[7] Dr. P Ravi Babu, K. Prapoorna et al., "multiobjective approach for feeder overloading and service restoration through reconfiguration”, IETECH, 2007.

[8] Dr. Ravi Babu, Sai Sushma et al., "a novel ACO based search approach to enhance the distribution system load balance", ICIIECS,2017.

[9] F.S. Pereira, K. Vittori, G.R.M. da Costa, "ant colony based method for reconfiguration of power distribution system to reduce losses", IEEE, 2008.

[10] Majid Jamil, Amit Sharma, "ant colony optimization for restoration of distribution system", IEEE, 2015.

[11] Firas M.F.Flaih, Lin Xiangning et al, "distribution system reconfiguration for power loss minimization and voltage profile improvement using modified particle swarm optimization”, 2016 IEEE PES.

[12] Inji Ibrahim atteya, Hamdy Ashour, "radial distribution network reconfiguration for power losses reduction using a modified particle swarm optimization", CIRED, 2017. 
[13] Soumitri Jena, Sushil Chauhan, "solving distribution feeder reconfiguration and concurrent DG installation problems for power loss minimization by multi swarm cooperative PSO algorithm", IEEE 2016.

[14] Tandon. A, Saxena. D, "a comparative analysis of SPSO \&BPSO for power loss minimization in distribution system using network reconfiguration", Proc. Int. Conf, Innovative applications of computational intelligence on power energy \&controls with their impact on humanity, November-2014, pp.226-232.

[15] S.Ganesh, R, Kanimozhu, "an effective soft computing technique for network reconfiguration in distribution system", ICACCCT, 2016.

[16] Dusharla Venkata Sunil, Narri Yadaiah, "a novel improved particle swarm optimization frame work for reconfiguration of radial distribution system", IEEE, India, 2017.

[17] A.V. Sudhakara Reddy, M.Damodar Reddy, M.Satish Kumar Reddy, "network reconfiguration of distribution system for loss reduction using GWO algorithm", International Journal of Electrical and Computer Engineering (IJECE), Vol.7, No.6, December2017, pp.3226-3234.

[18] S. Surender Reddy, "optimal reactive power scheduling using cuckoo search algorithm”, International Journal of Electrical and Computer Engineering (IJECE), Vol.7, No.5, October2017, pp.2349-2356.

[19] Lakshmi M, Ramesh Kumar A, "optimal reactive power dispatch using crow search algorithm", International Journal of Electrical and Computer Engineering (IJECE), Vol.8, No.3, June2018, pp.1423-1431.

[20] Surender Reddy Salkuti, "multi-objective based optimal energy and reactive power dispatch in deregulated electricity markets", International Journal of Electrical and Computer Engineering (IJECE), Vol.8, No.5, October2018, pp.3427-3435.

[21] Zeba Khan, Mahfooz Alam, Raza Abbas Haidri, "effective load balance scheduling schemes for heterogeneous distribution system", International Journal of Electrical and Computer Engineering (IJECE), Vol.7, No.5, October2017, pp.2757-2765.

[22] Dr.P.Ravi Babu, Sushma Pasunuru, Vaishnavi Gattu, "Solution of Multi Objective Problems for Weekly Meshed Distribution System through Genetic Algorithm”, International Conference on Recent Innovations in Electrical and Electronics Engineering, JNTU, Hyderabad, India.

[23] Dr. Pallikonda Ravi Babu, K. Anish Kumar, G. Charan Teja, "New Heuristic Search Approach to Enhance the Distribution System Load Balance”,2013 International Conference on Power, Energy and Control(ICPEC).

[24] Deepti Yadav, Arunima Verma, "Comperative Performance Analysis of PMSM Drive Using MPSO and ACO Techniques", International Journal of Power Electronics and Drive Systems (IJPEDS), Vol.9, No.4, December 2018, pp.1510-1522.

[25] Gagari Deb, Kabir Chakraborty, "Gauss Seidel Method based Voltage Security Analysis of Distribution System", International Journal of Electrical and Computer Engineering (IJECE), Vol.8, No.1, February 2018, pp.43-51.

\section{BIOGRAPHIES OF AUTHORS}

\begin{tabular}{|l|l|}
\hline & $\begin{array}{l}\text { Dr P. Ravi Babu is currently working as Professor in the department of Electrical and } \\
\text { Electronics Engineeringat SNIST, Ghatkesar, Telangana.He received his Ph.D. from JNTUH } \\
\text { in the year2010, Hyderabad, AP, India. He received his B.E. degree in Electrical and } \\
\text { Electronics Engineering in 1996 and M. Tech degree in Power Systems in 1999 from } \\
\text { National Institute of Engineering, Mysore University, Karnataka, India. His current area of } \\
\text { research is Demand Side Management and electrical energy conservation studies. His special } \\
\text { fields of interest include design of non conventional units for production of energy, } \\
\text { minimization of losses and service restoration in electrical distribution systems using Fuzzy } \\
\text { logic, Ant colony Algorithms,Bee colony algorithms,particle swarm optimization,Genetic } \\
\text { algorithms and Simulated Annealing techniques. }\end{array}$ \\
\hline & $\begin{array}{l}\text { Molughu Srivani received her B.Tech degree in Electrical and Electronics Engineering from } \\
\text { Aurora's Engineering College, Bhongiri, Jawaharlal Nehru Technological University, } \\
\text { Hyderabad, India. She is currenty pursuing her Masters of Technology in Electrical Power } \\
\text { Engineering from Sreenidhi Institute of Science and Technology, Jawaharlal Nehru } \\
\text { Technological University, Hyderabad, India. Her research interests power systems include } \\
\text { distribution system ohmic loss minimization and renewable energy sources applications. }\end{array}$ \\
\hline
\end{tabular}

